\title{
Amphisbaenia: Adaptações para o Modo de Vida Fossorial
}

\author{
Maria Eliana Carvalho Navega-Gonçalves ${ }^{1 *} \&$ João Paulo de Almeida Benites ${ }^{2}$ \\ ${ }^{1}$ Universidade Metodista de Piracicaba (Unimep), Piracicaba, SP, Brasil. \\ ${ }^{2}$ Universidade Estadual Paulista Júlio de Mesquita Filho (Unesp), Rio Claro, SP, Brasil. \\ *E-mail para correspondência: eliana.navega@gmail.com.br
}

\begin{abstract}
RESUMO
Amphisbaenia são répteis fossoriais, que vivem em sistemas de túneis construídos por eles mesmos. Atualmente, são descritas 195 espécies recentes. O objetivo deste estudo foi reunir informações bibliográficas sobre aspectos de sua morfologia, fisiologia e comportamento relacionando-as ao hábito fossorial. O principal instrumento de escavação dos anfisbênios é a cabeça, cuja morfologia está relacionada com a maneira como a escavação é realizada. Assim, nas espécies com a cabeça arredondada o mecanismo de escavação é generalizado e nas espécies com a cabeça em forma-de-pá, de espátula ou com uma quilha vertical é especializado. O crânio é resistente, formado por placas ósseas rígidas, que devem suportar as investidas da cabeça. $\mathrm{O}$ corpo é alongado e cilíndrico desprovido de membros, na maioria, e formado por anéis tegumentares, importantes no deslocamento retilíneo do corpo para a frente e para trás, dentro dos túneis. O alongamento do corpo é refletido nos órgãos internos que são, em sua maioria, alongados; os órgãos pares tendem a sofrer redução ou deslocamento unilateral. Como estratégias de defesa utilizam-se da autotomia caudal, exibição da cauda ou salto de fuga. São predadores que se alimentam, normalmente, de insetos e suas larvas, apreendidos por mandíbulas potentes, dentes fortes e recurvados. 0 sistema visual é reduzido, no entanto, são capazes de perceber sons e vibrações oriundas do substrato, e possuem um acurado senso químico. A maioria das espécies é ovípara com um baixo número de ovos por ninhada e o ciclo sexual é geralmente sazonal, sincronizado com a estação quente e chuvosa, mas outros aspectos relacionados ao comportamento reprodutivo das espécies ainda são desconhecidos. Exibem termorregulação comportamental e selecionam micro-habitat com temperaturas mais favoráveis às suas atividades, realizando migrações verticais no solo, de acordo com a temperatura ambiental e estações do ano. Os tipos de solos e o teor de umidade do mesmo parecem influenciar na distribuição espacial dos Amphisbaenia, mas esta relação precisa ser melhor compreendida. O modo de vida fossorial protege da irradiação solar intensa, oferece um micro-habitat com maior teor de umidade do que na superfície, propicia proteção contra muitos predadores e favorece a captura de presas que vivem no solo, mas impõe restrições em relação os biótopos onde este animais poderiam ser encontrados.
\end{abstract}

Palavras-chave: Adaptações fossoriais, Anfisbênios, Revisão bibliográfica.

\section{ABSTRACT}

Amphisbaenia: adaptations to the fossorial lifestyle. Amphisbaenia are fossorial reptiles, which live in tunnel systems built by themselves. Currently, 195 species are described. The objective of this study was to gather bibliographic information on aspects of their morphology, physiology and behavior related to the fossorial habit. The main digging tool of the amphisbaenians is the head, whose morphology is related to the way excavation is carried out. In round-headed species, the mechanism is generalized, and in species with a paddle-shaped head, a spatula or a vertical keel, is specialized. The skull is sturdy, consisting of rigid bony plates, which must support the head thrust. The body is elongated and cylindrical, devoid of limbs, mostly formed by integumentary rings, important in the rectilinear displacement of the body back and forth within the tunnels. The elongation of the body is reflected in the internal organs which are, for the most part, elongated; the paired organs tend to undergo unilateral reduction or displacement. As a defense strategy they use caudal autotomy, tail exhibit or escape jump. They are predators that normally feed on insects and their larvae, caught by powerful jaws, strong recurved teeth. The visual system is reduced; however, they can perceive sounds and vibrations from the substrate and have an accurate chemical sense. Most 
species are oviparous with a low number of eggs per litter and the sexual cycle is usually synchronized with the hot and rainy season; but other aspects related to the reproductive behavior of species are still unknown. They exhibit behavioral thermoregulation and microhabitat selection with temperatures more favorable to their activities, performing vertical migrations in the soil according to the environmental temperature and seasons. Soil types and soil water content seem to affect the spatial distribution of Amphisbaenia, but this relationship needs to be better studied. The fossorial life protects it from intense solar radiation, offers a micro-habitat with higher moisture content than does the surface, protects against many predators, and is advantageous for catching soil-dwelling preys; however, it imposes limitations on the biotopes where these animals could be found.

Keywords: Amphisbaenians, Bibliographic research, Fossorial adaptations.

\section{INTRODUÇÃO}

Amphisbaenia Gray, 1844 é um grupo de amniotas reptilianos de corpo cilíndrico e alongado, desprovido de membros, na maioria das espécies. Atualmente são descritas 195 espécies de ocorrência na região Neotropical, Afro-tropical e Mediterrânica (Uetz et al., 2019). São predominantemente fossoriais vivendo em sistemas de túneis construídos por eles mesmos, através de seus crânios altamente adaptados para a escavação (Gans 1968, 1969, 1974), o que os torna um exemplo excelente para o estudo de modificações sofridas por organismos que se adaptaram a um modo de vida em ambiente extremo (Gans, 1969).

O nome é de origem grega ("amphis", duplo; "baino", caminhar) e significa "deslocar-se em ambas as direções", devido à capacidade desses animais de se locomoverem para a frente e para trás, dentro de suas galerias (Gans, 1969; Cameron \& Gans, 1977). Esse hábito, aliado à semelhança entre a cauda e a cabeça de algumas espécies, originou o nome popular "cobra-de-duas-cabeças" (Cameron \& Gans, 1977). Outras denominações populares podem ser encontradas como "mãe-das-saúvas", que faz alusão à presença de algumas espécies em ninhos de formigas cortadeiras (Gans, 1969) e também "cobra-cega", devido aos olhos reduzidos. No entanto, o nome popular "cobra-cega" pode ser utilizado também para algumas serpentes (Serpentes) e para as cecílias (Amphibia) (Bernarde, 2012), o que eventualmente provoca confusões.

Uma revisão sobre as características e afinidades dos Amphisbaenia, comparadas com as de outros Lepidosauria, foi apresentada por Gans, em 1978, que discorreu também sobre a história da classificação do grupo, desde a primeira menção feita por Linné, em 1758. Embora muitos outros estudos tenham sido realizados sobre os anfisbênios desde então, aspectos relacionados à sua fisiologia e ao seu comportamento permanecem desconhecidos, principalmente no que se refere à reprodução. Muito provavelmente, a falta deste conhecimento se deve à dificuldade na obtenção de exemplares para estudos e na observação desses animais em seu ambiente natural, devido ao hábito fossorial (Andrade et al., 2006; Navega-Gonçalves, 2009).

Neste sentido, investigações recentes em campo e em condições experimentais, com esforço de 
coleta, além de resgates de fauna de aproveitamentos hidrelétricos, têm proporcionado o conhecimento de novas espécies e contribuído para a obtenção de dados ecológicos (Navega-Gonçalves, 2004; Pavan, 2007; Sehman et al., 2010; Balestrini \& Cappellari, 2011; López et al., 2013; Martin et al., 2013; Matias \& Verrastro, 2018), ampliando significativamente o conhecimento sobre o grupo.

Este estudo teve como objetivo reunir informações bibliográficas sobre aspectos da morfologia, fisiologia e do comportamento dos Amphisbaenia, de forma a destacar as adaptações morfológicas e fisiológicas para a vida fossorial e as implicações deste modo de vida no comportamento alimentar, de defesa, reprodutivo e de termorregulação das espécies estudadas e, ainda, se o tipo de solo influencia na distribuição das espécies de anfisbênios. Além da bibliografia consultada, alguns dados originais sobre o comportamento de algumas espécies também foram fornecidos.

\section{AGRUPAMENTO SISTEMÁTICO E DISTRIBUIÇÃO GEOGRÁFICA}

Os anfisbênios pertencem à Ordem Squamata, assim como os lagartos (Lacertilia) e as serpentes (Serpentes), mas diferem destes por apresentarem uma série de características peculiares e, por esta razão, sua posição taxonômica foi revista várias vezes (Gans, 1978). Hoje estão alocados no táxon Amphisbaenia, no entanto, suas relações filogenéticas dentro de Squamata ainda são incertas (Vidal \& Hedges, 2009). De acordo com os dados disponibilizados no site <reptiledatabase> (Uetz et al., 2019), 195 espécies de Amphisbaenia estão agrupadas em 6 famílias: Amphisbaenidae, Trogonophidae, Bipedidae, Rhineuridae, Blanidae e Cadeidae (Quadro 1).

As famílias Amphisbaenidae e Trogonophidae apresentam uma maior distribuição geográfica. A primeira contém o maior número de espécies descritas, 176 em 12 gêneros, de ocorrência na África, América do Sul e América Central. Os Trogonophidae, com seis espécies em quatro gêneros, ocorrem na África (Somália, Marrocos, Argélia e Tunísia) e no Oriente Médio (Irã, Iraque, Arábia Saudita, Qatar, Emirados Árabes, Omã, Yêmen) (Uetz et al., 2019). Por sua vez, a família Bipedidae possui um único gênero (Bipes) e três espécies, que são as únicas entre os anfisbênios a possuírem membros anteriores desenvolvidos; as mesmas estão restritas ao México (Kim et al., 1976; Papenfuss, 1982). Rhineuridae apresenta apenas uma espécie recente, Rhineura floridana, que ocorre nos Estados Unidos (Flórida e Geórgia) (Gans, 1967). Blanidae e Cadeidae são as duas famílias mais recentemente reconhecidas; a primeira, com sete espécies pertencentes ao gênero Blanus, de ocorrência na Espanha, Portugal, Marrocos (África), Grécia, Turquia, Síria e Líbano e a segunda, com duas espécies do gênero Cadea, restrita à Cuba (América Central) (Kearney, 2003; Vidal et al., 2008; Sindaco et al., 2014).

\begin{tabular}{|c|c|c|}
\hline Famílias/gêneros & Espécies citadas neste estudo & Forma da cabeça/cauda/viviparidade \\
\hline \multicolumn{3}{|c|}{ AMPHISBAENIDAE } \\
\hline
\end{tabular}




\begin{tabular}{|c|c|c|}
\hline \multicolumn{3}{|l|}{176 espécies em 12 gêneros } \\
\hline \multirow{5}{*}{ Amphisbaena Linné, 1758} & Amphisbaena alba Linnè, 1758 & $\begin{array}{l}\text { Cabeça arredondada, cauda curta sem anel de autotomia } \\
\text { (Gans, 1962a) }\end{array}$ \\
\hline & $\begin{array}{l}\text { Amphisbaena dubia Müller, } 1924 \\
\text { Amphisbaena fuliginosa Linné, } 1758 \\
\text { *Amphisbaena heterozonata Burmeister, } 1861 \text { (= A. darwini) } \\
\text { Amphisbaena lumbricalis Vanzolini, } 1996 \\
\text { Amphisbaena mertensi Strauch, } 1881 \\
\text { Amphisbaena munoai Klappenbach, } 1960 \\
\text { Amphisbaena nigricauda Gans, } 1966 \\
\text { Amphisbaena roberti Gans, } 1964 \\
\text { Amphisbaena rozei Lancini, } 1963 \\
\text { *Amphisbaena trachura Vanzolini } 2002 \text { (= A. darwini) } \\
\text { Amphisbaena vermicularis Wagler, } 1824\end{array}$ & $\begin{array}{l}\text { Cabeça arredondada, cauda com anel de autotomia } \\
\text { (exceto em A. dubia e A. roberti) (Vanzolini, 1991a, 2001; } \\
\text { Gans, 1966a) }\end{array}$ \\
\hline & *Anops kingii Bell, 1833 (= Amphisbaena kingii) & $\begin{array}{l}\text { Cabeça com quilha vertical, cauda com anel de autotomia } \\
\text { (Vanzolini, 1999) }\end{array}$ \\
\hline & *Aulura anomala Barbour, 1914 (= Amphisbaena anomala) & $\begin{array}{l}\text { Cabeça em forma de pá (pouco acentuada), cauda com } \\
\text { anel de autotomia (Gans, 1971a) }\end{array}$ \\
\hline & *Bronia bedai Vanzolini, 1991 (= Amphisbaena bedai) & $\begin{array}{l}\text { Cabeça arredondada (focinho proeminente), cauda com } \\
\text { anel de autotomia (Vanzolini, 1991b) }\end{array}$ \\
\hline & $\begin{array}{l}\text { *Cercolophia cuiabana Strussman \& Carvalho, } 2001 \\
\text { (= Amphisbaena cuiabana) }\end{array}$ & $\begin{array}{l}\text { Cabeça arredondada (focinho proeminente), cauda com } \\
\text { anel de autotomia (Strussmann \& Carvalho, 2001) }\end{array}$ \\
\hline Ancylocranium Parker, 1942 & 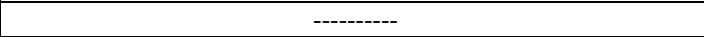 & 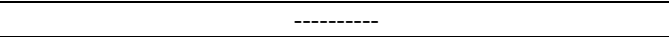 \\
\hline Baikia Gray, 1865 & 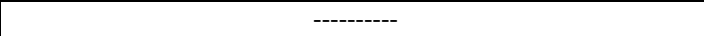 & --------- \\
\hline Chirindia Cott, 1934 & $\begin{array}{ll}-------- \\
\end{array}$ & 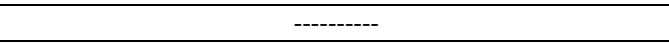 \\
\hline Cynisca Gray, 1844 & $\begin{array}{ll}------- \\
\end{array}$ & 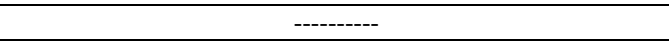 \\
\hline Dalophia Gray, 1865 & 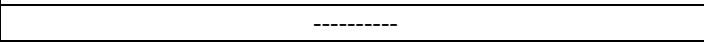 & 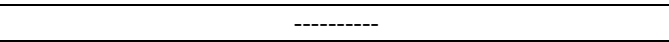 \\
\hline Geocalamus Günther, 1880 & 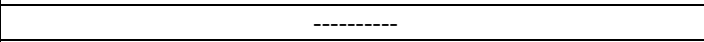 & 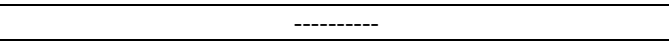 \\
\hline Leposternon Wagler, 1924 & $\begin{array}{l}\text { Leposternon infraorbitale (Berthold 1859) } \\
\text { Leposternon microcephalum Wagler, 1824 }\end{array}$ & $\begin{array}{l}\text { Cabeça em forma de pá, cauda curta sem anel de } \\
\text { autotomia (Gans, 1971b) }\end{array}$ \\
\hline Loveridgea Vanzolini, 1951 & Loveridgea ionidesii (Battersby, 1950) & $\begin{array}{l}\text { Cabeça arredondada (focinho proeminente) cauda com } \\
\text { anel de autotomia, vivípara (Gans \& Kraklau, 1989) }\end{array}$ \\
\hline Mesobaena Mertens, 1925 & 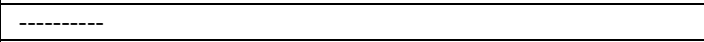 & 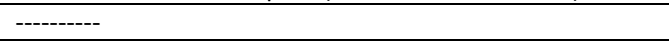 \\
\hline Monopeltis Smith, 1848 & $\begin{array}{l}\text { Monopeltis capensis Smith, } 1848 \\
\text { Monopeltis anchietae (Bocage, 1873) }\end{array}$ & $\begin{array}{l}\text { Cabeça em forma de pá, cauda curta sem anel de } \\
\text { autotomia, vivíparas (Broadley et al., 1976; Webb et al., } \\
\text { 2000) }\end{array}$ \\
\hline Zygaspis Cope, 1885 & Zygaspis quadrifrons (Peters, 1862) & $\begin{array}{l}\text { Cabeça arredondada, cauda com anel de autotomia } \\
\text { (Kearney, 2003) }\end{array}$ \\
\hline \multicolumn{3}{|c|}{ BIPEDIDAE } \\
\hline \multicolumn{3}{|l|}{3 espécies, 1 gênero } \\
\hline Bipes Latreille, 1802 & $\begin{array}{l}\text { Bipes biporus (Cope, 1894) } \\
\text { Bipes canaliculatus Bonnaterre, } 1789 \\
\text { Bipes tridactylus (Dugès, 1894) }\end{array}$ & $\begin{array}{l}\text { Cabeça arredondada e membros anteriores desenvolvidos, } \\
\text { cauda com anel de autotomia (Papenfuss, 1982) }\end{array}$ \\
\hline \multicolumn{3}{|c|}{ BLANIDAE } \\
\hline \multicolumn{3}{|l|}{7 espécies, 1 gênero } \\
\hline Blanus Wagler, 1830 & $\begin{array}{l}\text { Blanus cinereus (Vandelli, 1797) } \\
\text { Blanus mettetali Bons, } 1963\end{array}$ & $\begin{array}{l}\text { Cabeça arredondada, cauda com anel de autotomia } \\
\text { (Kearney, 2003) }\end{array}$ \\
\hline \multicolumn{3}{|c|}{ CADEIDAE } \\
\hline \multicolumn{3}{|l|}{2 espécies, 1 gênero } \\
\hline Cadea Gray 1844 & $\begin{array}{ll}-------- \\
\end{array}$ & $\begin{array}{ll}------- \\
\end{array}$ \\
\hline \multicolumn{3}{|c|}{ RHINEURIDAE } \\
\hline \multicolumn{3}{|l|}{1 espécie, 1 gênero } \\
\hline Rhineura Cope, 1861 & Rhineura floridana (Baird, 1858) & $\begin{array}{l}\text { Cabeça em forma de pá, cauda curta sem anel de } \\
\text { autotomia (Kearney, 2003) }\end{array}$ \\
\hline \multicolumn{3}{|c|}{ TROGONOPHIDAE } \\
\hline \multicolumn{3}{|l|}{6 espécies, 4 gêneros } \\
\hline Agamodon Peters, 1882 & $\begin{array}{l}\text { Agamodon anguliceps Peters, } 1882 \\
\text { Agamodon compressus Mocquard, } 1888\end{array}$ & \multirow{2}{*}{$\begin{array}{l}\text { Cabeça espatulada, cauda curta sem anel de autotomia } \\
\text { (Gans, 1960) }\end{array}$} \\
\hline Diplometopon Nikolski,1907 & Diplometopon zarudnyi Nikolski,1907 & \\
\hline Pachycalamus Günther, 1881 & 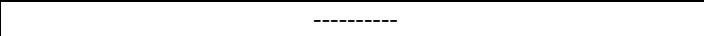 & 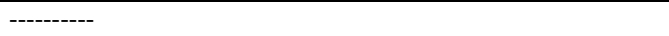 \\
\hline Trogonophis Kaup, 1830 & Trogonophis wiegmanni Kaup, 1830 & $\begin{array}{l}\text { Cabeça espatulada (menos acentuada), cauda curta sem } \\
\text { anel de autotomia, vivípara (Gans, 1960; Bons \& Saint } \\
\text { Girons, 1963) }\end{array}$ \\
\hline
\end{tabular}

Quadro 1. As seis famílias de Amphisbaenia com o número atual de espécies (195) e gêneros (segundo Uetz et al., 2019), em ordem alfabética. Espécies citadas neste estudo com indicação da forma da cabeça, cauda (presença ou ausência de autotomia) e ocorrência de viviparidade. Os nomes científicos das espécies foram mantidos conforme constam nos trabalhos consultados e na checklist de Gans (2005), mas as mudanças taxonômicas foram indicadas (*) com base em Uetz et al. (2019). 


\section{ADAPTAÇÕES MORFOLÓGICAS E FISIOLÓGICAS PARA O MODO DE VIDA FOSSORIAL}

Animais que passam a vida toda ou a maior parte dela sob o solo são denominados subterrâneos e a maioria constrói túneis sendo, portanto, chamados de escavadores (Hildebrand \& Goslow, 2006). Tal modo de vida é descrito como fossorial (do latim fossor, cavador) e requer características particulares, como as que serão descritas para os Amphisbaenia.

\section{Cabeça e crânio}

O principal instrumento de escavação dos Amphisbaenia é a cabeça, que realiza a penetração no solo e a confecção do túnel. Desta forma, estes animais conseguem ocupar com sucesso solos cuja compactação os torna inadequados para outros répteis (Gans, 1968). A morfologia da cabeça está relacionada com a maneira como a escavação é realizada. Nas espécies com a cabeça (ou focinho) mais ou menos arredondada o mecanismo de escavação é generalizado e, nas espécies com a cabeça em forma de pá, de espátula ou com uma quilha vertical é especializado (Gans, 1968, 1974) (Quadro 1).

As espécies com focinho arredondado escavam forçando suas cabeças dentro do solo em uma série de golpes dirigidos para a frente (Gans, 1974), semelhante a um aríete. São a maior parte das espécies conhecidas, por exemplo, Amphisbaena mertensi (Figura 1.1). As formas com cabeça arredondada vivem próximas à superfície, onde o solo é relativamente mais fácil de ser escavado (Gans, 1969).

Três mecanismos especializados foram considerados por Gans $(1968,1969,1974)$. O primeiro é utilizado pelas espécies com o focinho em forma de pá, como visto em Leposternon microcephalum (Figura 1.2) e que foi descrito em detalhes por Barros-Filho et al. (2008) e Hohl et al. (2014). Os autores observaram que o ciclo escavatório ocorre em três ou quatro etapas, iniciando com a região gular e a parte anterior do corpo do animal estáticas sobre o substrato do túnel, em seguida o corpo recua e a cabeça é inclinada para baixo, com o focinho tocando o piso. A cabeça, então, se movimenta de forma contínua para cima e para a frente, compactando os grãos do solo contra o teto do túnel, enquanto o corpo, em movimento sigmoide, comprime a região peitoral contra o piso do túnel, compactando os grãos removidos do teto.

O segundo mecanismo é realizado por espécies com o focinho quilhado verticalmente, como em "Anops" kingii (atualmente Amphisbaena kingii, cf. Mott \& Vieites, 2009) (Figura 1.3) e que forçam a extremidade do túnel com o mesmo ou com a porção lateral do pescoço, para comprimir o material contra as paredes, o que provoca o alargamento do túnel (Gans, 1968, 1974). 


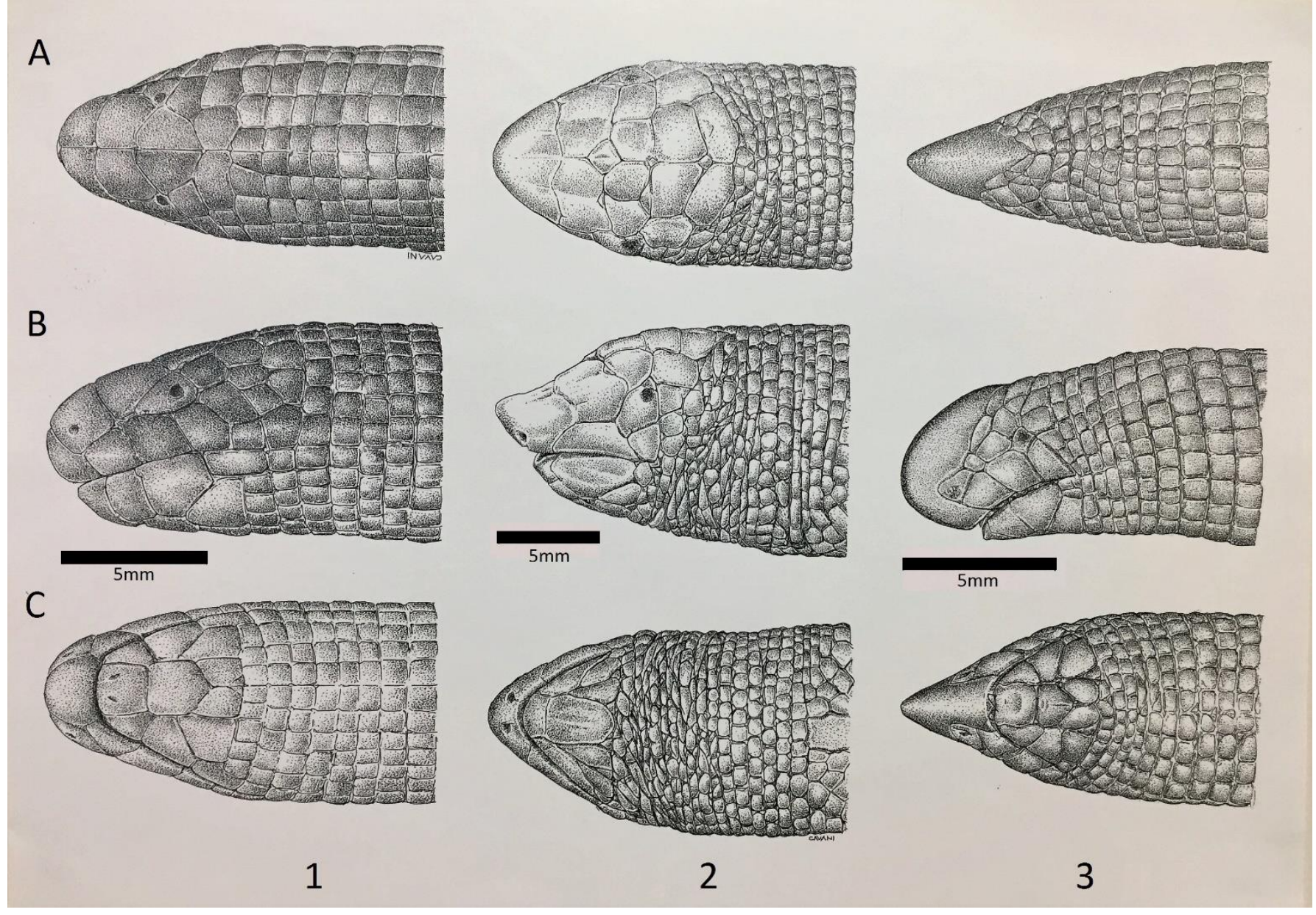

Figura 1. Representação dos três tipos de cabeça. A - vista dorsal, B - vista lateral, C - vista ventral. (1) cabeça arredondada (Amphisbaena mertensi), (2) cabeça em forma de pá (Leposternon microcephalum), (3) cabeça em forma de quilha (A. kingii). Ilustração de Cavani Rosas (modificado de Navega-Gonçalves, 2002).

O terceiro mecanismo é exibido pelos trogonofídeos, que possuem o focinho espatulado. A cabeça oscila para a direita e esquerda alternadamente raspando os grãos de areia do substrato e compactandoos na parede do túnel, como visto em Agamodon anguliceps (Figura 2), a espécie considerada mais especializada entre os Trogonophidae (Gans, 1974).

Consequentemente, o crânio destes escavadores deve suportar as investidas da cabeça. O crânio é robusto, formado por placas ósseas rígidas, geralmente sobrepostas e com ligações interdigitais na região frontal, o que lhes dá maior adesão e resistência contra os impactos sofridos pela cabeça durante a escavação (Zangerl, 1944; Vanzolini, 1951; Gans, 1974; Gans \& Montero, 2008). De um modo geral, o crânio divide-se em dois segmentos: o segmento facial (anterior, que inclui a região do focinho) e o segmento occipital, posterior, que se liga à coluna vertebral. O segmento facial é menor e mais estreito que o segmento occipital (também denominado cranial) e curvado para baixo de maneira a formar, com o eixo longitudinal, um ângulo crânio-facial. Este difere entre as espécies em maior ou menor grau e as maiores adaptações são vistas nas formas especializadas, que escavam solos mais compactados e profundos (Zangerl, 1944; Vanzolini, 1951; Gans, 1974; Viera et al., 1980; Maisano et al., 2006). Outras 
características peculiares relativas ao crânio foram descritas e comparadas entre várias espécies de Amphisbaenia por Gans \& Montero (2008), que relacionaram as variações encontradas ao modo de escavação.

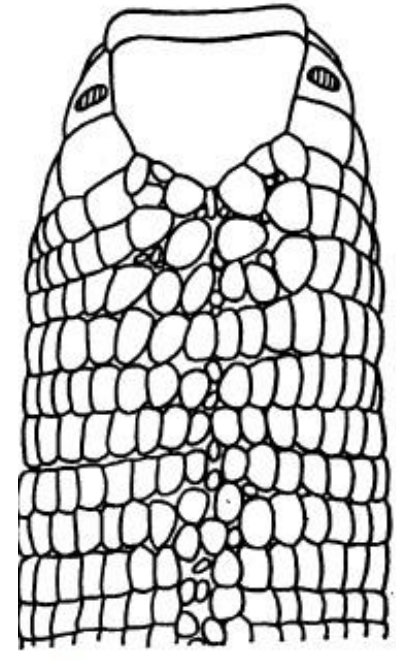

A

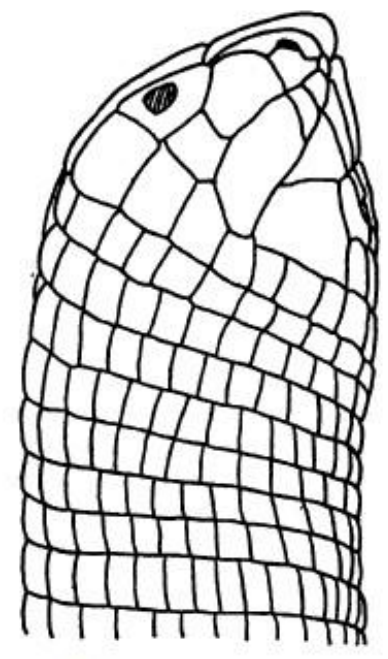

$\mathrm{B}$

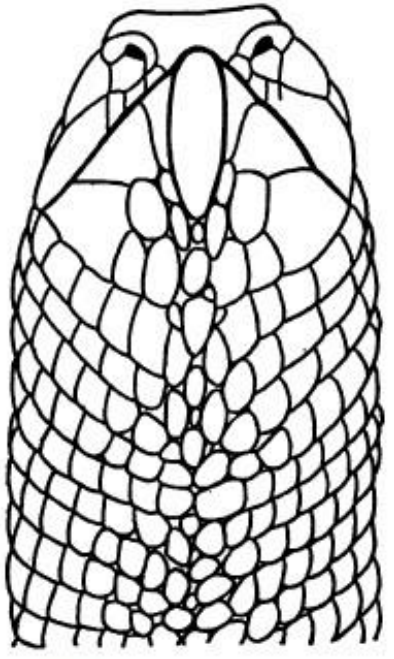

C

Figura 2. Representação da cabeça em forma de espátula de Agamodon anguliceps (Trogonophidae). A - vista dorsal, B - vista lateral, C - vista ventral (modificado de Gans, 1960).

Segundo Vanzolini (1951) existe uma correlação entre a forma do focinho e a escutelação cefálica. As regiões da cabeça envolvidas na penetração no solo e, portanto, expostas ao desgaste da superfície mostram fusão dos escudos de forma que, nas espécies com focinho arredondado, em geral, a superfície dorsal da cabeça, a ponta e os lados da mandíbula são revestidos por escudos maiores (Gans, 1974). No entanto, nas espécies com focinho em forma de pá, de espátula e com quilha vertical há uma tendência para maior fusão dos escudos cefálicos que, por terem um tamanho aumentado, diminuem o atrito com o solo. Tais áreas da cabeça tendem a ser altamente queratinizadas (Vanzolini, 1951, 1999; Gans, 1971b; Gans, 1974).

Apesar da classificação em formas generalistas e especialistas, há uma variedade de tipos de crânios dentro dos Amphisbaenia e vários grupos morfológicos distintos podem ser reconhecidos (Gans \& Montero, 2008), assim como formas de escavação intermediárias podem ser consideradas entre os mecanismos citados (Gans, 1968). As espécies com cabeça arredondada representam o grupo mais diversificado de anfisbênios, tanto em número de espécies quanto em distribuição geográfica, sendo que esta forma da cabeça parece ser adequada para uma variedade de ambientes distintos (Gans, 1990; Gans \& Montero, 2008; Vidal et al., 2008), enquanto as formas especializadas estariam adaptadas a solos mais profundos e compactados, por consequência, mais difíceis de serem escavados (Gans, 1969, 1974, 1990). 


\section{Locomoção}

Os anfisbênios se deslocam de três maneiras: por locomoção através de ondulação lateral, por locomoção em concertina e por locomoção retilínea (Gans, 1962b). Os três mecanismos podem ser utilizados na superfície, embora a locomoção retilínea seja utilizada apenas dentro dos túneis, pela maioria deles (Gans, 1978).

A locomoção por ondulação lateral ocorre através de movimentos alternados para esquerda e direita, na forma de curvas serpentiformes. O animal posiciona partes do corpo sobre objetos no substrato, tais como galhos e rochas, utilizando-os como "ponto de apoio", favorecendo o deslocamento para a frente (Gans, 1962b, 1974). O movimento é contínuo e à medida que as ondas se propagam pelo corpo, este se desloca seguindo a trilha orientada pela cabeça (Hildebrand \& Goslow, 2006).

Na locomoção em concertina ou sanfonada, o animal se dispõe em uma ou mais alças em forma de "S". As alças de trás pressionam o substrato, de forma que seja forçado para baixo e para trás, aumentando o atrito, para evitar o deslizamento do corpo. O animal avança a cabeça sem tocar no substrato, porém antes de perder a estabilidade, a parte anterior toca no solo, formando uma nova região estacionária, dando suporte para que a porção posterior seja deslocada para a frente, mantendo um ciclo semelhante a uma "sanfona" (Gans, 1962b, 1974; Hildebrand \& Goslow, 2006).

A locomoção retilínea, embora limite a velocidade, é vantajosa porque permite o deslocamento em túneis estreitos e implica em um movimento simétrico e orientado para a frente, onde o corpo é mantido em uma linha reta. Durante o movimento, seções da pele são puxadas para a frente, entram em contato com o solo e fornecem pontos estacionários, enquanto o corpo se desloca através do túnel (Gans, 1962b, 1974).

\section{Forma do corpo e tegumento}

Os membros estão ausentes, exceto nas espécies do gênero Bipes (Bipedidae), que possuem os anteriores desenvolvidos e que são utilizados para a penetração no solo, enquanto a escavação é realizada pela cabeça, como nos demais anfisbênios (Gans, 1969). A redução ou perda total dos membros em Amphisbaenia está intrinsecamente associada com o alongamento do corpo e redução de seu diâmetro, o que facilita sua passagem por locais estreitos durante o processo de escavação (Gans, 1960, 1975).

O corpo alongado e cilíndrico é formado por anéis tegumentares, bem definidos e subdivididos em segmentos (escamas), que têm importância fundamental no deslocamento retilíneo do corpo para a 
frente e para trás, como descrito anteriormente. O movimento cutâneo ocorre através da contração da pele a nível de cada sutura inter-anular, de forma que os anéis se expandem discretamente em diâmetro e a pele "se dobre para fora" entre cada sutura, o que facilita o contato com a parede do túnel, à medida que o animal se move através do sinuoso sistema de galerias, por locomoção retilínea (Gans, 1960, 1962b, 1969). Esse tipo de deslocamento implica em algumas mudanças estruturais em relação à pele, que se apresenta frouxamente conectada com a musculatura esquelética, cerca de $360^{\circ}$, ao redor da circunferência do corpo (Gans, 1962b).

Sendo assim, a pele da região do corpo é quase desprovida de conexões com os tecidos subjacentes, de forma que os músculos integumentares se ligam à mesma apenas no ponto de sutura de cada anel. Desta forma, ao serem contraídos, a coluna vertebral pode ser movida a uma distância considerável, evitando o atrito entre o animal e a parede do túnel, durante o movimento da cabeça e do tronco para a frente (Gans, 1960, 1974). Corroborando estas informações, foi observado que em Amphisbaena mertensi a pele da região do corpo está frouxamente ligada à musculatura subjacente o que, inclusive, facilita a sua remoção, enquanto na região da cabeça encontra-se fortemente aderida aos ossos cranianos (Navega-Gonçalves \& Souza, 2001), devido ao uso da mesma como instrumento de penetração no solo e subsequente escavação. A textura lisa do tegumento também diminui o atrito ao redor do animal, além de proteger contra partículas do meio e parasitas, que eventualmente possam ferir a pele (Gans, 1975).

A disposição das escamas presumivelmente facilita o contato da pele com a parede do túnel (Gans, 1974). Segundo Barros-filho (1994) pode-se inferir que as escamas são mais longas do que largas na superfície dorsal para conferir maior firmeza no momento de contato com as paredes do túnel, evitando o deslizamento. Ao contrário, as escamas são mais largas do que longas ventralmente, diminuindo o contato com o substrato e promovendo um deslocamento com um mínimo de atrito.

A densidade e o padrão de pigmentação da pele também estão relacionados ao hábito fossorial. Espécies mais densamente pigmentadas, ocupam galerias mais superficiais nos solos, saindo para fora do túnel regularmente. Aquelas com ausência ou baixa pigmentação cutânea ocupam solos mais profundos (Gans, 1969, 1974). Gans (1974) relatou a diferença na pigmentação entre duas espécies que ocupam a mesma área geográfica (simpátricas) na Somália: $A$. anguliceps encontrada próxima à superfície tem uma coloração geral amarelada, com algumas manchas castanhas, que corresponde à cor da areia do local, enquanto Agamodon compressus, um cavador profundo, possui a pele despigmentada. Jared et al. (1998) também compararam o padrão de pigmentação de Amphisbaena alba e L. microcephalum, a primeira, uma espécie frequentemente encontrada na superfície do solo, possui a pele densamente pigmentada, enquanto a segunda, encontrada somente nas galerias no solo, é praticamente desprovida de pigmento 
cutâneo.

O desgaste da pele nestes animais escavadores é intenso e compensado por meio das sucessivas ecdises ("troca de pele") que sofrem (Hildebrand \& Goslow, 2006). Segundo os mesmos autores referindose aos répteis, de um modo geral, tal fenômeno ocorre várias vezes ao ano e parece estar sob controle hormonal, podendo ser influenciado pela umidade. Alguns estudos mostram que o tegumento dos anfisbênios é permeável à água e que pode haver perda de água através do mesmo, principalmente no período de muda (Bogert \& Cowles, 1947; Krakauer et al., 1968; Cloudsley-Thompson, 1977; Sawaya \& Aguiar, 1982).

\section{Autotomia caudal e outras estratégias de defesa}

A cauda dos anfisbênios pode ser curta e grossa, como em A. alba (Gans, 1962a) ou longa e delgada, como em A. mertensi (Gans, 1966b; Navega-Gonçalves, 1997), mas outras características da mesma são relatadas. Nos trogonofídeos a ponta da cauda é afilada (Gans, 1960), em Rhineura floridana é espatulada (Gans, 1967), em “Cercolophia” Vanzolini, 1992 (atualmente gênero Amphisbaena cf. Mott \& Vieites, 2009) a cauda possui uma quilha vertical terminal (Vanzolini, 1992; Strussmann \& Carvalho, 2001) e em Amphisbaena rozei estão presentes tubérculos dorsais (Costa et al., 2018).

A cauda pode estar envolvida em estratégias de defesa, sendo assim, muitas espécies de anfisbênios apresentam autotomia caudal (Gans, 1978) ou auto-amputação voluntária da cauda, como estratégia defensiva para fugir da predação (Clouse \& Capaldi, 2006). O local de autotomia caudal é, usualmente, caracterizado por um anel mais estreito, curto e diversamente pigmentado (Gans \& Alexander, 1962). A posição do anel de autotomia varia interespecificamente e é um dos critérios utilizados na taxonomia do grupo. No entanto, pode variar também intraespecificamente, como observado em A. mertensi (Gans, 1966b; Navega-Gonçalves, 1997) e em outros anfisbenídeos estudados (Vanzolini, 2002)

Papenfuss (1982) associou o comprimento da cauda e a frequência de perda da mesma à pressão de predação, uma vez que Bipes canaliculatus e Bipes tridactylus, mais sujeitos à predação, possuem caudas mais longas quando comparados com Bipes biporus de cauda curta. Um dos principais predadores de Bipes é a cobra Micrurus Wagler, 1824 (Serpentes, Elapidae) encontrada nos locais de ocorrência de $B$. canaliculatus e B. tridactylus, mas ausente na área de ocorrência de B. biporus.

Embora o mecanismo não tenha sido investigado em anfisbênios, vários estudos foram feitos em lagartos, mostrando que a cauda autotômica possui adaptações estruturais, que agem para minimizar a perda de sangue e o trauma sofrido pelos tecidos adjacentes, promovendo rapidamente a cicatrização da ferida (Gilbert et al., 2013). Em A. mertensi observou-se que os tecidos ao redor da vértebra que sofre a 
fratura estão frouxamente unidos e a pele, nesta região, se rompe com facilidade, o que explica o processo aparentemente fácil de quebra da cauda pelo animal (Navega-Gonçalves, 1997). A função parece clara: ao desprender parte da cauda, o anfisbênio ameaçado por um predador pode fugir, enquanto este se distrai com a mesma, que continua a se movimentar rapidamente, de um lado para o outro. Tal comportamento, de desprendimento e movimentação da cauda seguida da fuga do animal, foi observado em um espécime de $A$. mertensi em um parque de Piracicaba, SP (obs. pess.), corroborando as informações de Gans (1974) e de Papenfuss (1982), sendo que o último também relatou o movimento das caudas autotomizadas de $B$. tridactylus, para trás e para a frente, por vários minutos após a quebra, o que daria ao anfisbênio um tempo adicional para escapar do predador.

Diferentemente do que acontece na pós-autotomia caudal em lagartos diversos, a cauda dos anfisbênios não se regenera (Gans, 1978). Alguns pesquisadores argumentam que, embora a autotomia da cauda seja um meio eficaz de fuga em lagartos estudados, poderia reduzir a sobrevida do animal, uma vez que o mesmo se tornaria mais susceptível a futuros ataques de predadores (Daniels et al., 1986; Clouse \& Capaldi, 2006; Bateman \& Fleming, 2009), principalmente no caso dos anfisbênios, cujas caudas amputadas não são regeneradas.

Entre os trogonofídeos a autotomia caudal está totalmente ausente (Gans, 1960), assim como nas espécies de cauda curta, que podem apresentar outras estratégias defensivas, principalmente quando se encontram fora dos túneis, quando ficam mais vulneráveis ao ataque de predadores.

Amphisbaena alba, quando provocada, levanta a cauda ao mesmo tempo em que levanta a cabeça assumindo uma postura que se assemelha a uma ferradura e tal movimento é acompanhado pela abertura da boca em atitude ameaçadora (Ditmars, 1910 apud Clousdley-Thompson, 1977; Gorzula et al., 1977). Embora esse comportamento tenha sido interpretado por Ditmars (1910) como um inofensivo blefe, Cloudsley-Thompson (1977) observou que o anfisbênio contra-ataca com uma mordida, relatando que foi mordido pelo mesmo, que prendeu seus dentes sobre sua pele com uma torção lateral do corpo, como um crocodilo faz ao se alimentar na água. Jared et al. (1998) associaram o comportamento de exibição da cauda pela espécie com o fato de a mesma ser frequentemente encontrada na superfície do solo e, portanto, mais exposta à predação, em comparação com L. microcephalum, um cavador profundo, que não apresenta exibição de cauda. Exibição da cauda foi relatada também em Amphisbaena fuliginosa, que ao ser tocada levanta a cauda em um arco, com a ponta dirigida anteriormente, movimentando-a para a frente e para trás (Greene, 1973).

Andrade et al. (2006) relataram mordida e defecação como comportamento defensivo exibido por adultos e filhotes de $A$. mertensi. Uma outra estratégia, que pode ser considerada como defensiva, é o salto de fuga que foi observado nos trogonofídeos, quando perturbados. Segundo a descrição feita por 
Gans (1974), o animal salta e fica em uma posição de "S" no chão, com a cabeça e a cauda enroladas para dentro. A cauda serve de ponto de partida para um novo salto, de forma que a parte anterior se levanta do solo no início de cada ciclo. Um tipo de salto semelhante foi observado em espécimes de $A$. mertensi, em Piracicaba, SP, que se encontravam em locais onde não podiam se enterrar, como em áreas pavimentadas (obs. pess.). O mesmo comportamento foi observado em indivíduos de Amphisbaena vermicularis ao serem removidos momentaneamente do terrário em que estavam acondicionados e colocados sobre o chão pavimentado (obs. pess.). Pode-se inferir que tal comportamento dificultaria a captura ou o ataque da anfisbena por um predador promovendo seu afastamento do mesmo, de forma rápida, até encontrar um local para se enterrar.

\section{Morfologia interna e demandas funcionais}

Um recente estudo realizado por Westphal et al. (2019) indicou que a perda da cintura escapular e dos membros em anfisbênios (exceto em Bipes) levou à modificação dos locais de fixação dos músculos associados à esta região e que estavam conectados ao esqueleto na condição ancestral. Assim, os músculos da região da cintura escapular e peitoral são mantidos, à despeito da redução óssea, mas apresentam deslocamento para áreas não esqueléticas, como músculos circundantes, tecido conjuntivo ou pele. Os autores sugerem que os rearranjos evolutivos observados nestes músculos foram impulsionados por demandas funcionais e não por restrições de desenvolvimento.

Outras características morfológicas internas estão relacionadas ao hábito escavador, como a evidenciada na posição das costelas, que praticamente se unem ventralmente, em relação à linha mediana do corpo, principalmente nas regiões cardíaca e hepática, constituindo-se em uma rígida proteção aos órgãos internos (Navega-Gonçalves \& Souza, 2001), impactados ao longo do processo de escavação e deslocamento dentro das galerias no solo.

A perda ou redução de membros também está associada ao alongamento do corpo e à redução do diâmetro do mesmo em relação ao comprimento total, o que parece favorecer o hábito fossorial (Gans, 1975). Como consequência, os órgãos na cavidade visceral dos anfisbênios são, em sua maioria, alongados e dispostos de forma a se acomodar em um corpo comprido e com diâmetro reduzido. Sendo assim, os órgãos pares tendem a sofrer redução ou deslocamento unilateral, de forma que testículos e ovários direitos, com seus respectivos ductos e acompanhados da glândula adrenal estão em posição mais anterior, na cavidade visceral, em relação aos mesmos órgãos do lado esquerdo. Em relação aos pulmões, ocorre a redução ou perda unilateral do pulmão direito, como observado em várias espécies (Gans, 1975; Crook \& Parsons, 1980; Navega-Gonçalves \& Souza, 2001; Navega-Gonçalves, 2009), mostrando que essa 
é uma característica peculiar do grupo, como já havia sido assinalado por Butler (1895).

O pulmão esquerdo, por sua vez, é um órgão saculiforme de grandes proporções, no qual pode-se distinguir duas regiões morfologicamente distintas: a primeira, anterior, é esponjosa, enquanto a posterior é reticulada e semitransparente (Smalian, 1884; Navega-Gonçalves \& Souza, 2001; Navega-Gonçalves, 2009; Navega-Gonçalves \& Silva, 2013) e, com base nestas características, foi atribuída uma função de reserva de ar para a região posterior do pulmão (Smalian, 1884). Porém, os estudos conduzidos por Navega-Gonçalves \& Silva (2013) mostraram que a despeito da redução de trabéculas e favéolos (divisões do parênquima pulmonar e câmaras respiratórias, respectivamente), na porção posterior do pulmão esquerdo, há a presença de muitos capilares evidenciando sítios de trocas gasosas, o que indica que o pulmão pode ser considerado inteiramente funcional para as trocas gasosas e funcionar também como reservatório de ar. Tais características permitiriam a sobrevivência dos anfisbênios nas galerias no solo, sob condições de baixa renovação de ar.

Gans (1978) relacionou a redução gradual do pulmão direito ao aumento nas modificações associadas à escavação, uma vez que nos trogonofídeos Agamodon e Diplometopon, considerados cavadores mais especializados, este órgão está mais reduzido do que em Trogonophis, gênero menos especializado (Gans, 1960). No entanto, ao contrário do que foi relatado pelo autor, nos Amphisbaenidae estudados por Navega-Gonçalves (2009) o pulmão direito está reduzido ou ausente nas espécies consideradas menos especializadas (com cabeça arredondada), tais como A. vermicularis, "Bronia" bedai (Amphisbaena bedai, cf. Mott \& Vieites, 2009) e "Cercolophia" cuiabana (Amphisbaena cuiabana, cf. Mott \& Vieites, 2009). Nos escavadores mais especializados, Navega-Gonçalves (2009) constatou que, além do pulmão direito ser menos reduzido, o pulmão esquerdo atinge maiores proporções, quando comparados aos pulmões esquerdos das demais espécies, como foi observado em A. kingii, L. microcephalum e "Aulura" anomala (Amphisbaena anomala cf. Mott \& Vieites, 2009). Crook \& Parsons (1980) também registraram o pulmão direito menos reduzido em Monopeltis, de solo profundo, quando comparado a Zygaspis quadrifrons, habitante de superfície. É possível considerar, então, que um maior volume pulmonar possui, consequentemente, uma maior área para trocas gasosas e para a reserva de ar, favorecendo os escavadores de solos mais profundos e compactados, onde a disponibilidade de oxigênio é menor (Navega-Gonçalves, 2009).

\section{Hábitos alimentares e dentição}

Os anfisbênios são predadores muito bem-sucedidos que se alimentam de insetos e suas larvas, de vermes e até de pequenos mamíferos, apreendidos por mandíbulas potentes, dentes fortes e 
recurvados (Pregill, 1984). A dentição é usualmente pleurodonte, exceto nos trogonofídeos, que são acrodontes (Zangerl, 1944; Vanzolini, 1951; Gans, 1960). Uma característica peculiar é a presença de um grande dente central pré-maxilar, que se encaixa entre os dentes anteriores da mandíbula (Gans, 1969; 1974). A fórmula dentária varia entre as espécies (Zangerl, 1944; Vanzolini, 1951) e algumas variações individuais no número de dentes também foram observadas (Pregill, 1984; Navega-Gonçalves, 1997).

Na superfície do solo, o animal se aproxima da presa com as mandíbulas abertas e dá a mordida, retirando pedaços. Quando está dentro das galerias, o anfisbênio imobiliza a presa contra a parede do túnel, usando o próprio corpo e, da mesma forma que relatado acima, retira pedaços com a mordida. A rígida estrutura crânio-mandibular, junto a uma potente musculatura temporal, além de permitir a retirada de pedaços de animais diversos, consegue triturar peças esqueléticas (Gans, 1969). Nos anfisbênios mais especializados, no entanto, os crânios são mais curtos e as mandíbulas reduzidas, de forma que são menos eficazes no ataque às presas (Gans, 1969). Tal característica é refletida no comportamento defensivo dos anfisbênios assim, Barros-Fillho (1994) observou que $A$. mertensi é mais agressiva e tenta morder ao ser manipulada, enquanto L. microcephalum não demonstra nenhuma agressividade ao ser manuseada, corroborando observações realizadas em exemplares de ambas as espécies mantidas em terrários para estudos (cf. Navega-Gonçalves, 1997, 2002).

Com relação à dieta, há uma predominância de cupins (Isoptera), larvas de besouros (Coleoptera) e formigas (Formicidae) como itens alimentares mais predados em várias espécies de anfisbênios em que o conteúdo estomacal foi examinado (Broadley et al., 1976; Cabrera \& Merlini, 1990; Cusumano \& Powell, 1991; Cruz-Neto \& Abe, 1993; Webb et al., 2000; Bernardo-Silva et al., 2006; Balestrini \& Cappellari, 2011). A predominância destes insetos pode ser explicada pela abundância dos mesmos no ambiente onde os anfisbênios são encontrados, pois alguns destes vivem associados com cupinzeiros e formigueiros (Bernardo-Silva et al., 2006). A captura de presas pequenas e de hábitos gregários é facilitada, ocorrendo sem maior custo energético, haja vista que estão disponíveis em grandes quantidades no ambiente (Balestrini \& Cappellari, 2011).

Outros itens alimentares foram encontrados tais como: insetos dípteros, lepidópteros, hemípteros, além de aracnídeos, anelídeos, moluscos e até vertebrados (Cabrera \& Merlini, 1990; Cusumano \& Powell, 1991; Cruz-Neto \& Abe, 1993; Gil et al., 1993; Colli \& Zamboni, 1999; Webb et al., 2000; Bernardo-Silva et al., 2006; Balestrini \& Cappellari, 2011; Martin et al., 2013) indicando hábito alimentar generalista e oportunista (Cabrera \& Merlini, 1990; Cusumano \& Powell, 1991; Webb et al., 2000; Martin et al., 2013). O último item citado (vertebrados) foi relatado como presente na dieta de $A$. alba, uma das maiores e mais robustas espécies entre os anfisbênios (Colli \& Zamboni, 1999).

O tamanho reduzido da presa também facilita a captura e ingestão, uma vez que os anfisbênios 
possuem uma abertura bucal proporcionalmente menor do que a de outros répteis (Bernardo-Silva et al., 2006; Balestrini \& Cappellari, 2011). No entanto, López et al. (2013) identificaram estratégias distintas utilizadas por Blanus cinereus para captura de presas de tamanhos diversos e concluíram que uma dieta diversificada poderia permitir aos anfisbênios explorarem recursos tróficos subterrâneos variáveis, contornando as restrições impostas pela fossorialidade.

\section{Órgãos sensoriais e sentidos: fotorrecepção, mecanorrecepção e quimiorrecepção}

Um meio subterrâneo possibilita boa detecção acústica e olfativa, mas não visual (Gans, 1969). Assim, animais que vivem em ambientes com baixa ou nenhuma luminosidade tendem a ter os olhos rudimentares, como os animais fossoriais (Foreaux et al., 2010).

Os olhos dos anfisbênios são pequenos e, geralmente, visíveis através de uma escama modificada (escama ocular), que não difere em aparência das demais que recobrem a cabeça, mas que, histologicamente, revela uma pele fina e translúcida, sugerindo uma possível adaptação para a passagem de luz. A retina, embora rudimentar, possui as camadas típicas encontradas em outros vertebrados, sugerindo algum papel na recepção e processamento da luz (Foreaux et al., 2010) ou fotorrecepção.

Segundo Duke-Elder (1958), o tamanho do globo ocular está relacionado com o modo de vida do animal, de forma que os animais que não necessitam de agilidade apresentam uma tendência evolutiva para redução do tamanho dos olhos. Para Foreaux et al. (2010) essa hipótese é plausível ao assumir que os animais fossoriais não estão sujeitos à mudanças ambientais súbitas ou à modificações abruptas relacionadas à predação, o que exigiria agilidade e, então, precisão visual.

A anatomia funcional do ouvido dos Amphisbaenia foi estudada em algumas espécies (Gans \& Wever, 1972; Wever \& Gans, 1973; Gans \& Wever, 1975). Não há ouvido externo, mas o tegumento associado às estruturas internas óticas conduzem as vibrações do solo, que são transmitidas ao longo do aparelho columelar, formado por uma extracolumela cartilaginosa ligada a uma columela óssea (ouvido médio) que, por sua vez, transmite o som para o ouvido interno (Gans \& Wever, 1972; Wever \& Gans, 1973). Segundo os mesmos autores, a extracolumela está localizada na região da mandíbula e fixada à pele da região das escamas infralabiais. Em Bipes biporus e em Blanus cinereus a extracolumela está ausente, de forma que a columela faz a conexão entre a superfície receptora do som na pele, passando pelo tecido conjuntivo subjacente e o ouvido interno (Wever \& Gans, 1972; Gans \& Wever, 1975).

Os estudos citados mostram que os anfisbênios possuem uma boa sensibilidade auditiva, sendo assim, é possível que localizem suas presas pelo som. Tal comportamento foi observado nos anfisbenídeos A. mertensi e A. vemicularis mantidos em terrários, de tal forma que, alguns minutos após se colocar 
tenébrios (Coleoptera) vivos na superfície do solo, os anfisbênios saíam dos túneis e se deslocavam pela superfície na direção das presas (obs. pess.).

Mas é a quimiorrecepção o sentido fundamental para a discriminação entre o que pode ser alimento e o que não é, uma vez que os anfisbênios possuem um acurado sentido químico (Saint Girons, 1971). A língua é bífida e se projeta continuamente para fora da boca com movimentos para cima e para baixo, tocando no substrato, de forma a recolher partículas do meio e direcioná-las para o órgão vomeronasal, localizado na parte superior da cavidade oral, e que testa quimicamente o meio (Hildebrand \& Goslow, 2006). Semhan et al. (2010) verificaram que Amphisbaena heterozonata pode discriminar, com base em estímulos químicos, entre alimento e água, que é oferecida como controle. Ao receber estímulos oriundos de cupins e larvas de tenébrios, itens de presas dos quais se alimentam no ambiente natural e oferecido em cativeiro, os anfisbênios fizeram significativamente mais movimentos de língua para estes estímulos do que para a água e, também, responderam mais prontamente aos primeiros. Outro anfisbênio, B. cinereus, também foi capaz de discriminar entre quatro presas, mostrando preferência por minhocas (López \& Salvador, 1994).

López \& Martin $(1994,2001)$ demostraram, ainda, que B. cinereus foi capaz de discriminar entre odores de espécies de formigas e responder agressivamente aos estímulos de formigas perigosas, além de detectar e discriminar odores de potenciais predadores, como a serpente Coronella girondica (Daudin, 1803) (Colubridae) ou agressores, como a centopéia do gênero Scolopendra Linnaeus, 1758 (Scolopendridae) exibindo uma resposta defensiva correspondente.

Nas espécies fossoriais com visão reduzida o sentido químico é essencial, não só para a identificação da presa e de predadores, como apresentado acima, mas também para a reprodução. Anfisbênios possuem glândulas pré-cloacais, que produzem feromônios relacionados ao reconhecimento intraespecífico (Cooper et al., 1994; López et al., 1997; López \& Martin, 2001; López \& Martin, 2005). Estudos conduzidos com $A$. alba demostraram que à medida que esses animais se deslocam pelos túneis, os poros pré-cloacais raspam no substrato promovendo a liberação das secreções das glândulas e formando uma trilha olfativa, constituindo-se em um meio eficiente de comunicação intraespecífica no interior dos túneis (Antoniazzi et al.,1993, 1994; Jared et al., 1999).

\section{Reprodução}

Os hábitos reprodutivos destes escavadores são conhecidos para poucas espécies, a maioria das quais é ovípara, tais como espécies dos gêneros Amphisbaena, Leposternon e Blanus analisados por Andrade et al. (2006) e Santos (2013). Viviparidade foi relatada para Trogonophis wiegmanni (Bons \& Sain 
Girons, 1963), Monopeltis capensis (Broadley et al., 1976, sendo que os autores usam o termo “ovoviviparidade"), Loveridgea ionidesii (Gans \& Kraklau, 1989) e sugerida para Monopeltis anchietae (Webb et al., 2000).

Espécies ovovivíparas retêm seus ovos no interior do corpo até a eclosão dos filhotes, que são nutridos pelo vitelo, embora não haja ovipostura, uma vez que existe a tendência da redução ou eliminação das cascas dos ovos. Por esta razão, elas não são claramente distintas das espécies vivíparas, cujos embriões são nutridos pelos tecidos maternos (Hildebrand \& Goslow, 2006). Assim, o termo "viviparidade" tem sido usado para ambas as situações, pela maioria dos pesquisadores (Blackburn, 1982).

Segundo Andrade et al. (2006), o conhecimento atual sobre o assunto indica que a evolução da viviparidade em Amphisbaenia ficou restrita às espécies africanas. Quais seriam as vantagens da viviparidade para os anfisbênios é uma questão que ainda não possui uma resposta definitiva, mas é possível especular sobre o assunto. Assim, Packard et al. (1977) argumentaram que a viviparidade poderia trazer benefícios térmicos aos embriões dentro do corpo de um genitor capaz de termorregulação comportamental ou, ainda, aumentar as chances de proteção dos ovos (retidos no interior do corpo) contra predadores de ninhos e/ou patógenos encontrados no solo. No entanto, argumentações teóricas sugerem que o número limitado de espécies vivíparas entre os Amphisbaenia pode ser devido aos hábitos fossoriais, que restringiriam a evolução desta característica, uma vez que a distensão do corpo durante a gestação poderia prejudicar a locomoção nas galerias dentro do solo (Shine, 1985).

O padrão reprodutivo geral em Amphisbaenia é caracterizado por um baixo número de ovos/embriões por ninhada, entre dois e seis, não excedendo oito (Andrade et al., 2006), embora em uma fêmea de Amphisbaena trachura tenha sido contado nove ovos (Santos, 2013). Os ovos são grandes, se comparados ao tamanho do corpo adulto, alongados e dispostos linearmente dentro da cavidade abdominal (Andrade et al., 2006; Balestrin \& Cappellari, 2011; Santos, 2013). A baixa produção reprodutiva parece ser compensada pela eclosão de grandes juvenis, com maiores chances de sobrevivência e uma rápida maturação (Balestrin \& Cappellari, 2011).

Na maioria das espécies, a reprodução é sincronizada com a estação quente e chuvosa e parece variar com a latitude (Andrade et al., 2006; Santos, 2013). Santos (2013) identificou ciclos reprodutivos sazonais para as fêmeas, com evidência de bienalidade, para a maioria das espécies analisadas (Amphisbaena alba, A. dubia, A. munoai, A. mertensi, A. trachura, A. kingii, Leposternon microcephalum e Trogonophis wiegmanni). Para os machos, a mesma autora também identificou ciclos sazonais para a maioria das espécies investigadas (Amphisbaena dubia, A. munoai, A. mertensi, A. trachura, A. kingii, Leposternon infraorbitale, L.microcephalum, Blanus cinereus, B. mettetali e Trogonophis wiegmanni), no entanto, com diferenças em relação à duração e época das fases de espermatogênese, armazenamento 
de esperma e hipertrofia do segmento sexual renal.

Um período de incubação de cerca de dois meses parece ser a regra para os anfisbênios ovíparos (Andrade et al., 2006). Segundo dados obtidos pelos autores, ovos de A. alba, A. fuliginosa, A. mertensi, A. kingii, e L.microcephalum foram encontrados em ninhos de formigas ou de cupins, o que poderia oferecer a vantagem de um micro-habitat com temperatura e umidade estáveis e proteção contra potenciais predadores.

Dimorfismo sexual em relação ao tamanho corporal, largura da cabeça, comprimento da cauda e presença/ausência de poros-pré-cloacais foi relatado para algumas espécies de anfisbênios. Fêmeas maiores que os machos foram verificadas, por exemplo, em Amphisbaena munoai e A. kingii (Balestrin \& Cappellari, 2011; Santos, 2013), em A. alba (Colli \& Zamboni, 1999), A. mertensi, A. roberti e A. trachura (Santos, 2013) e também em Zygaspis quadrifrons (Webb et al., 2000). No entanto, em Leposternon infraorbiltale (Santos, 2013) e Amphisbaena nigricauda (Lima et al., 2014) os machos são maiores. Em A. nigricauda os machos, além de maiores, possuem cabeças mais largas que as fêmeas, que não possuem poros pré-cloacais (Lima et al., 2014), ressaltando as diferenças entre os sexos. Machos mais pesados e com cabeças maiores também foram verificados em T. wiegmanni (Martin et al., 2012). Maior tamanho entre os machos pode indicar competição entre os mesmos pelo acesso às fêmeas, enquanto fêmeas maiores podem refletir o aumento na fecundidade (Lima et al., 2014), ou seja, maior espaço na cavidade visceral para a produção de ovos.

Em A. munoai (Balestrin \& Cappellari, 2011), A. anomala, L. infraorbiltale (Santos, 2013) e T. wiegmanni (Martin et al., 2012) os machos adultos possuem caudas maiores que as fêmeas adultas o que, segundo os autores citados, poderia estar relacionado à acomodação do hemipênis e seus músculos retratores no interior da cauda. No entanto, todos os anfisbênios possuem hemipênis e estas diferenças não foram observadas em outras espécies analisadas. Segundo Martin et al. (2012), uma cauda mais longa nos machos poderia ser vantajosa nas lutas intra-sexuais ou durante o acasalamento. Porém, a falta de um padrão na ocorrência ou não de dimorfismo sexual entre os Amphisbaenia evidencia a necessidade de mais estudos que possam elucidar tais questões.

\section{Ritmos de atividade, termorregulação e uso do solo}

Os anfisbênios estudados exibem uma atividade mais intensa durante o período chuvoso e com temperaturas mais amenas sendo encontrados na superfície, durante o dia, geralmente embaixo de pedras, troncos, folhas ou outros objetos (Gil et al., 1993; Diaz-Paniagua et al., 1995; López et al., 2002; Balestrin \& Cappellari, 2011; Matias \& Verrastro, 2018). No entanto, as três espécies do gênero Bipes 
raramente foram encontradas sobre a superfície (Papenfuss, 1982). Atividade noturna em campo foi registrada para B. cinereus (Diaz-Paniagua et al., 1995), Diplometopon zarudny (Al-Johany, 1999) e $A$. munoai (Matias \& Verrastro, 2018). A presença desses animais na superfície está relacionada com a necessidade de obtenção de temperaturas favoráveis para a realização de suas atividades, pois sendo ectotérmicos dependem de fontes externas de calor (Schmidt-Nielsen, 2002).

As variações de temperatura exercem efeitos consideráveis em vários processos fisiológicos e, dentro de limites, uma elevação de temperatura acelera a maioria destes processos (Schmidt-Nielsen, 2002) permitindo, desta forma, que o animal se torne ativo para se alimentar ou fugir de um predador, por exemplo. A regulação da temperatura é, portanto, uma atividade que afeta o desempenho fisiológico, reprodutivo e ecológico (Huey, 1982).

O calor usado para aumentar a temperatura do corpo em animais ectotérmicos deve vir da exposição ao sol ou do contato com objetos aquecidos (Pough et al., 2008). No caso dos anfisbênios, o calor é obtido pelo contato com as rochas ou com o próprio solo superficial, processo denominado de tigmotermia (Martin et al., 1990; López et al., 1998, 2002), mas a biologia termal e os aspectos relacionados à mesma foram investigados em apenas algumas espécies de Amphisbaenia: Bipes $\mathrm{sp}$ (Papenfuss, 1982); A. mertensi (Abe, 1984), Blanus cinereus (Martín et al., 1990, 1991; Gil et al., 1993; López et al., 1998), T. wiegmanni (Gatten \& McClung, 1981; López et al., 2002; Civantos et al., 2003 ), Z. quadrifrons (Hailey \& Elliot, 1995) e A. munoai (Matias \& Verrastro, 2018).

Os estudos conduzidos com $B$. cinereus em uma área de clima temperado na Espanha mostraram que existe uma forte correlação entre as temperaturas corporais e as temperaturas do substrato, o que é esperado para um animal de hábito subterrâneo. Esses anfisbênios foram encontrados sob rochas, que apresentam uma temperatura mais alta que a do ambiente circundante, durante o período da manhã, sendo raramente encontrado nos horários mais quentes do dia. No início da manhã, quando a temperatura é baixa, os animais são pouco ativos, mas à medida que a temperatura do substrato aumenta, sua temperatura corporal também se eleva, permitindo que se movam próximo à superfície e sob as rochas. Eles também selecionam rochas de diferentes tamanhos em momentos diversos do dia e, durante o verão, quando as temperaturas são mais altas, selecionam rochas maiores mantendo-se sob as mesmas por períodos mais curtos. A vegetação e as folhas acumuladas sobre o solo propiciam ambientes sombreados, que poderiam ser usados nas horas mais quentes do dia (Martin et al., 1990, 1991; López et al., 1998).

Resultados semelhantes foram obtidos para T. wiegmanni, no Norte da África (Civantus et al., 2003), para Bipes, no México (Papenfuss, 1982) e para A. munoai, no Sul do Brasil (Matias \& Verrastro, 2018) mostrando que os anfisbênios selecionam micro-habitats térmicos, deslocando-se horizontalmente 
ou verticamente no substrato. Quando as condições térmicas não são favoráveis, podem se deslocar para áreas mais profundas no solo, buscando variações de temperatura no substrato, que os permitam continuar ativos por mais tempo (Papenfuss, 1982; Martin et al., 1990; López et al., 2002). Segundo Balestrin \& Cappellari (2011) o padrão de distribuição sazonal exibido por A.munoai e A. kingii pode ser explicado pela busca de uma temperatura corporal ideal, fazendo com que esses anfisbênios migrem verticalmente no solo entre as áreas mais frescas e profundas abaixo da superfície, durante o verão, e em áreas mais quentes próximas à superfície, durante o inverno.

Embora as temperaturas corporais dos anfisbênios estudados sejam mais baixas do que as registradas para lagartos heliotémicos, suas temperaturas são mais elevadas do que as temperaturas ambientais evidenciando termorregulação comportamental (Papenfuss, 1982; Abe, 1984, Martín et al., 1990; Gil et al., 1993; Hailey \& Elliot, 1995; López et al., 1998; Al-Johany, 1999; López et al., 2002; Civantos et al., 2003; Matias \& Verrastro, 2018). Pode-se inferir que temperaturas mais altas otimizam o forrageamento e estejam também relacionadas ao alto custo energético da escavação e da locomoção subterrânea, como mencionados por Gatten \& McClung (1981), Kamel \& Gatten (1983) e Tossini et al. (1994).

A falta de umidade no solo, na estação seca, é um fator que contribui para a ausência de indivíduos na superfície e um recuo mais profundo no solo evitaria as altas temperaturas próximo à superfície, além da obtenção de umidade em camadas mais profundas do solo (Bons \& Saint Girons, 1963; Papenfuss, 1982; Abe, 1984; Martin et al., 1990). Um solo seco é também mais compactado, o que poderia dificultar a escavação por algumas espécies (Martin et al., 1991).

Poucos estudos foram realizados com o intuito de compreender a relação entre o tipo de solo e o uso dos mesmos pelas espécies de Amphisbaenia, um aspecto que chama atenção, uma vez que estes animais passam a maior parte de sua existência em galerias construídas no solo. O estudo realizado por Martin et al. (2013), nas Ilhas Chafarinas (localizada ao Norte da Costa Marroquina e pertencente à Espanha) mostrou que algumas características físicas e químicas do solo determinam o uso de microhabitat por T. wiegmanni. Esses anfisbênios selecionaram solos relativamente arenosos, básicos, carbonatados e rasos, cobertos por rochas de média dimensão, ao passo que evitaram solos marinhos com textura salinizada, mais ácidos e mais profundos e aqueles cobertos principalmente por pequenas rochas. Blanus cinereus também foi encontrado, com maior frequência, em solos mais arenosos (em Madri, na Espanha) evitando aqueles com alto teor de argila (Martin et al., 1991). Bipes também constrói suas tocas em solos arenosos encontrados nas regiões do México onde as espécies ocorrem (Papenfuss, 1982).

No Brasil, Amphisbaena lumbricalis foi encontrada predominantemente habitando solos arenosos 
no bioma Caatinga (Vanzolini, 1996) e, mais recentemente, também em solos de textura arenosa, argilosa e arenosa/argilosa, em Pernambuco (Tavares et al., 2017), enquanto espécimes de A. alba e A. vermicularis foram registrados em solos arenosos em Minas Gerais (Porto et al., 2000), embora tenham sido encontradas também em solos não arenosos, na Bahia (Barros Filho \& Valverde, 1996).

A textura tem grande influência no comportamento físico-hídrico e químico do solo e é expressa pela proporção dos componentes granulométricos, areia, argila e silte, que fazem parte da fase mineral do solo (Embrapa, s/d). Assim, o solo pode ser classificado como arenoso (com granulação grossa) ou argiloso (com granulação fina), de acordo com as quantidades destes componentes encontrados e, embora a caracterização e classificação dos solos seja bem mais complexa do que a relatada (cf. Embrapa, s/d), de um modo geral, um solo com textura arenosa é mais permeável à água e seca com mais facilidade, enquanto o de textura argilosa permite uma infiltração mais lenta de água, mantendo o solo úmido por mais tempo (Lepsch, 2010). Sendo assim, solos arenosos são mais fáceis de cavar, enquanto os argilosos dificultam a movimentação, quando estão encharcados ou quando secam totalmente.

A umidade do solo parece ser um fator mais crítico do que a temperatura na distribuição dos anfisbênios (Bogert \& Cowles, 1947; Gans, 1968; Abe, 1984). É provável que habitem preferencialmente solos com boa drenagem, mas que não permaneçam encharcados por muito tempo, o que os obrigaria a buscar a superfície. As características do solo devem permitir, ainda, a construção e a manutenção dos túneis, bem como o deslocamento dos animais em seu interior (Gans, 1968). Sendo répteis adaptados à escavação, como descrito ao longo deste trabalho, é provável que as características do solo influenciem neste processo, mas essa relação ainda precisa ser melhor elucidada.

\section{CONSIDERAÇÕES FINAIS}

Os Amphisbaenia apresentam características que são claramente adaptações morfofuncionais para a escavação e fossorialidade. O modo de vida fossorial oferece vantagem na medida em que os protege da irradiação solar intensa, oferecendo um micro-habitat com maior teor de umidade do que na superfície. Além disso, propicia proteção contra muitos predadores encontrados na superfície e favorece a captura de presas que vivem no solo, no entanto, impõe restrições em relação aos biótopos onde estes animais poderiam ser encontrados. Os estudos indicam ainda que os anfisbênios apresentam um acurado senso químico e que são capazes de captar vibrações no solo; possuem termorregulação comportamental, de forma a selecionar micro-habitat com temperaturas mais favoráveis às suas atividades, realizando migrações verticais no solo de acordo com a temperatura ambiental e estações do ano, como o ciclo sexual sincronizado com a estação quente e chuvosa. Os tipos de solos e a umidade dos mesmos são 
características importantes na construção do túneis e parecem influenciar na distribuição espacial dos Amphisbaenia, mas a compreensão desta relação precisa ser melhor estudada, assim como alguns aspectos do comportamento reprodutivo, que são desconhecidos para a maioria das espécies.

\section{REFERÊNCIAS BIBLIOGRÁFICAS}

Abe, A.S. 1984. Experimental and field record of preferred temperature in the neotropical amphisbaenid Amphisbaena mertensii Strauch (Reptilia, Amphisbaenidae). Comparative Biochemistry and Physiology Part A: Physiology 77: 251-253.

Al-Johany, A.M. 1999. The activity and thermal biology of the fossorial reptile, Diplometopon zarudnyi (Amphisbaenia:Trogonophiidae) in Central Saudi Arabia. Asiatic Herpetological Research 8: 1-6.

Andrade, D.V.; Nascimento, LB. \& Abe, A.S. 2006. Habits hidden underground: a review on the reproduction of the Amphisbaenia with notes on four neotropical species. Amphibia-Reptilia 27: 207-217. Antoniazzi, M.M.; Jared, C.; Pellegrini, C.M.R. \& Macha, N. 1993. Epidermal glands in Squamata: morphology and histochemistry of the precloacal glands in Amphisbaena alba (Amphisbaenia). Zoomorphology 113: 199-203.

Antoniazzi, M.M.; Jared, C. \& Junqueira, L.C.U. 1994. Epidermal glands in Squamata: fine structure of precloacal glands in Amphisbaena alba (Amphisbaenia, Amphisbaenidae). Journal of Morphology 221: 101109.

Balestrin, R.L. \& Cappellari, L.H. 2011. Reproduction and feeding ecology of Amphisbaena munoai and Anops king (Amphisbaenia, Amphisbaenidae) in the Escudo Sul-Rio-Grandense, southern Brazil. Iheringia, Série Zoologia 101(1-2): 93-102.

Barros-Filho, J.D. 1994. Distribuição e análise morfológica do gênero Leposternon Wagler, 1824 no Estado do Rio de Janeiro, Brasil (Reptilia, Amphisbaenia). Dissertação (Mestrado em Zoologia). Universidade Federal do Rio de Janeiro, RJ. 91p.

Barros-Filho, J.D. \& Valverde, M.C.C. 1996. Nota sobre os Amphisbaenia (Reptilia: Squamata) da microrregião de Feira de Santana, estado da Bahia, Brasil. Sitientibus 14: 57-68.

Barros-Filho, J.D.; Hohl, L.S.L. \& Rocha-Barbosa, O. 2008. Excavatory Cycle of Leposternon microcephalum Wagler, 1824 (Reptilia, Amphisbaenia). International Jornal of Morphology 26(2): 411-414.

Bateman, P.W. \& Fleming, P.A. 2009. To cut a long tail short: a review of lizard caudal autotomy studies carried out over the last 20 years. Journal of Zoology 277: 1-14.

Bernarde, P.S. 2012. Anfíbios e répteis: Introdução ao Estudo da Herpetofauna Brasileira. Curitiba, Anolisbooks. 318p. 
Bernardo-Silva, J.S.; Von-Mühlen, E.M.; Di-Bernardo, M. \& Ketterl, J. 2006. Feeding ecology in the small neotropical amphisbaenid Amphisbaena munoai (Amphisbaenidae) in southern Brazil. Iheringia, Série Zoologia 96: 487-489.

Blackburn, D.G. 1982. Evolutionary origins of viviparity in the Reptilia. I. Sauria. Amphibia-Reptilia 3: 185205.

Bogert, C.M. \& Cowles, R.B. 1947. Moisture loss in relation to habitat selection in some floridian reptiles. American Museum Novitates 1358: 1-34.

Bons, J. \& Saint-Girons, H. 1963. Ecologie et cycle et sexuel des amphisbéniens du Maroc. Bulletin de la Sociétè des Sciences Naturelles et Physiques du Maroc 43: 117-170.

Broadley, D.G.; Gans, C. \& Visser, J. 1976. Studies on amphisbaenians (Amphisbaenia, Reptilia). 6. The genera Monopeltis and Dalophia in southern Africa. Bulletin of the American Museum of Natural History 157: 313-485.

Butler, G.W. 1895. On the complete or partial suppression of the right lung in the amphisbaenidae and of the left lung in snakes and snake-like lizards and amphibians. Proceedings of the Zoological Society of London, 1895: 691-712.

Cabrera, M.R. \& Merlini, H. 1990. The diet of Amphisbaena darwinii heterozonata in Argentina. Herpetological Review 21: 53.

Cameron, H.D. \& Gans, C. 1977. The Amphisbaena of antiquity: thoughts about the origin of the name. British Journal of Herpetology 5: 603-606.

Civantus, E.; Martín, J. \& López, P. 2003. Fossorial life constrains microhabitat selection of the amphisbaenian Trogonophis wiegmanni. Canadian Journal Zoology 81: 1839-1844.

Cloudsley-Thompson, J.L. 1977. Some aspects of biology of Amphisbaena alba L. British Journal of Herpetology 5(8): 617-621.

Clouse, A.R. \& Capaldi, E.A. 2006. Caudal autotomy and regeneration in lizards. Journal of Experimental Zoology 305a: 965-973.

Colli, G.R. \& Zamboni, D.S. 1999. Ecology of the Worm-Lizard Amphisbaena alba in the Cerrado of Central Brazil. Copeia 3: 733-742.

Costa, H.C.; Señaris, J.C.; Rojas-Runjaic, F.J.M.; Zaher, H. \& Garcia, P.C.A. 2018. Redescription of the rare South American worm lizard Amphisbaena rozei (Squamata: Amphisbaenidae). Amphibia-Reptilia 39(1): 21-30.

Crook, M.J. \& Parsons, T. 1980. Visceral anatomy of the Amphisbaenia. Journal of Morphology 163: 99133.

Cooper, W.E.; López, P. \& Salvador, A. 1994. Pheromone detection by an amphisbaenían. Animal Behaviour 
47(6): 1401-1411.

Cruz-Neto, A.P. \& Abe, A.S. 1993. Diet composition of two syntopic species of neotropical amphisbaenians, Cercolophia roberti and Amphisbaena mertensii. Journal of Herpetology 27: 239-240.

Cusumano, M.A. \& Powell, R. 1991. A note on the diet of Amphisbaena gonovensis in the Dominican Republic. Amphibia-Reptilia 12(3): 350-352.

Daniels, C.B.; Flaherty, S.P. \& Simbotwe, M.P. 1986. Tail size and effectiveness of autotomy in a lizard. Journal of Herpetology 20(1): 93-96.

Diaz-Paniagua, C.; Blazquez, M.C.; Keller, C.; Andreu, A.C.; Olmedo, G. \& Mateo, J.A. 1995. Observations on seasonal and dial surface activity of the amphisbaenian Blanus cinereus in south-western Spain. Herpetological Journal 5: 217-220.

Duke-Elder, S. 1958. The eye in evolution. In: Duke-Elder, S. (ed). System of Ophthalmology. London, Henry Kimpton. v. 1. 843p.

Embrapa. Empresa Brasileira de Pesquisa Agropecuária. Ministério da Agricultura, Pecuária e Abastecimento. Embrapa solos. Sistema Brasileiro de Classificação de Solos (SiBCS). Disponível em: <https://www.embrapa.br/solos/sibcs/ >. Acesso em: 28 mar. 2019.

Foureaux, G.; Egami, M.I.; Jared, C.; Antoniazzi, M.M.; Gutierre, R.C. \& Smith, R.L. 2010. Rudimentary eyes of Squamate fossorial reptiles (Amphisbaenia and Serpentes). The Anatomical Record 293: 351-357.

Gans, C. 1960. Studies on amphisbaenids (Amphisbaenia, Reptilia). 1. A taxonimic revision of the Trogonophidae, and a functional interpretation of the amphisbaenid adaptative pattern. Bulletin of the American Museum of Natural History 119: 129-204.

Gans, C. 1962a. Notes on Amphisbaenids (Amphisbaenia, Reptilia). 5. A redefinition and a bibliography Amphisbaenia alba Linné. Americam Museum Novitates 2105: 1-31.

Gans, C. 1962b. Terrestrial locomotion without limbs. American Zoologist 2(2): 167-182.

Gans, C. 1966a. Studies on amphisbaenids (Amphisbaenia, Reptilia). 3. The small species from Southern South America identified as Amphisbaena darwini. Bulletin of the American Museum of Natural History 134(3): 185-260.

Gans, C. 1966 b. Redescription of Amphisbaena mertensi Strauch, with comments on its geografhic variation and synonymy (Amphisbaenia: Reptilia). Copeia 3: 534-548.

Gans, C. 1967. Rhineura floridana. Catalogue of American Amphibians and Reptiles, p. 43. Disponível em: <https://repositories.lib.utexas.edu/handle/2152/44969>. Acesso em: 27 fev. 2019.

Gans, C. 1968. Relative success of divergent pathways in amphisbaenian specialization. The American Naturalist 102(926): 345-362.

Gans, C. 1969. Los anfisbenios, interesante grupo de reptiles minadores. Endeavour 28: 146-151. 
Gans, C. 1971a. Redescription of three monotypic genera of amphisbaenians from South America: Aulura Barbour, Bronia Gray, and Mesobaena Mertens. American Museum Novitates 2475: 1-32.

Gans, C. 1971b. Studies on amphisbaenids (Amphisbaenia, Reptilia). 4. A revision of the amphisbaenid genus Leposternon. Bulletin of the American Museum of Natural History 144(6): 379-464.

Gans, C. 1974. Biomechanics: An Approach to Vertebrate Biology. Philadelphia, J. B. Lippincott \& Co. $261 p$.

Gans, C. 1975. Tetrapod limblessness: evolution and functional corollaries. American Zoologist 15(2): 455467.

Gans, C. 1978. The characteristics and affinities of the Amphisbaenia. Transactions of the Zoological Society of London 34: 347-416.

Gans, C. 1990. Patterns in amphisbaenian biogeography: a preliminary analysis, pp.133-143. In: Peters, G. \& Hutterer, R. (eds.). Vertebrates in the Tropics. Bonn, Museum Alexander Koenig.

Gans, C. \& Alexander, A. 1962. Studies on amphisbaenids (Amphisbaenia, Reptilia). 2. On the amphisbaenids of the Antilles. Bulletin of the Museum of Comparative Zoology 128: 65-158.

Gans, C. \& Kraklau, D.M. 1989. Studies on amphisbaenids (Reptilia). 8. Two genera of small species from east Africa (Geocalamus e Loveridgea). American Museum Novitates 2944: 1-28.

Gans, C. \& Montero, R. 2008. An Atlas of Amphisbaenian Skull Anatomy, pp. 621-738. In: Gans, C.; Gaunt, A.S. \& Adler, K. (eds). Biology of the Reptilia. Ithaca, Society for the Study of Amphibians and Reptiles. v. 21.

Gans, C. \& Wever, E.G. 1972. The ear and hering in Amphisbaenia (Reptilia). Journal of Experimental Zoology 179: 17-34.

Gans, C. \& Wever, E.G. 1975. The amphisbaenian ear: Blanus cinereus and Diplometopon zarudnyi. Proceedings of the National Academy of Sciences of the United States of America 72: 1487-1490.

Gatten, R.E. \& McClung, R.M. 1981. Thermal selection by an amphisbaenian Trogonophis wiegmanni. Journal Thermal Biology 6: 49-51.

Gil, M.J.; Guerrero, F. \& Pérez-Mellado, V. 1993. Observations on morphometrics and ecology in Blanus cinereus (Reptilia: Amphisbaenia). Journal of Herpetology 27: 205-209.

Gilbert, E.A.B.; Payne, S.L. \& Vickaryous, M.K. 2013. The anatomy and histology of caudal autotomy and regeneration in lizards. Physiological and Biochemical Zoology, 86(6): 631-644.

Gorzula, S.; Salazar, C. \& Rendon, D. 1977. Aspects of the ecology of Amphisbaena alba Linnaeus in the Venezuelan Guayana. British Journal of Herpetology 5: 623-626.

Greene, H.W. 1973. Defensive tail display by snakes and amphisbaenians. Journal of Herpetology 7(3): 143-161. 
Hailey, A. \& Elliot, M. 1995. Thermorregulation of the amphisbaeniam Zygaspis quadrifrons. Herpetological Journal 5: 281-284.

Hildebrand, M. \& Goslow, G.E. Jr. 2006. Análise da Estrutura dos Vertebrados. 2 ed. São Paulo, Atheneu Editora. 637p.

Hohl, L.S.L.; Loguercio, M.F.C.; Buendia, R.A.; Almeida-Santos, M.; Viana, L.A.; Barros-Filho, J.D. \& RochaBarbosa, O. 2014. Fossorial gait pattern and performance of a shovel-headed amphisbaenian. Journal of Zoology 294: 234-240

Huey, R.B. 1982. Temperature, physiology and ecology of reptiles, pp. 25-91. In: Gans, C., Pough, F.H. \& Harvey, F. (eds.). Biology of the Reptilia. New York, Academic Press. v.12.

Jared, C.; Antoniazzi, M.M.; Freymüller, E. \& Junquerira, L.C.U. 1998. A possible advantage of displaying the tail: a comparison between the tail and body integument structure in Amphisbaena alba and Leposternon microcephalum (Squamata, Amphisbaenia). Annales des Sciences Naturelles 2: 89-97

Jared, C.; Antoniazzi, M.M.; Silva, J.R.M.C. \& Freymüller, E. 1999. Epidermal glands in Squamata: microscopical examination of pre-cloacal glands in Amphisbaena alba (Amphisbaenia, Amphisbaenidae). Journal of Morphology 241: 197-206.

Kamel, S. \& Gatten, R.E. 1983. Aerobic and anaerobic activity metabolism of limbless and fossorial reptiles. Physiological and Biochemical Zoology 56: 419-429.

Kim, Y.J.; Gorman, J.; Papenfuss, T.J. \& Roychoudhury, A.K. 1976. Genetic relationships and genetic variation in the amphisbaenian genus Bipes. Copeia 1976(1):120

Krakauer, T.; Gans, C. \& Paganelli, C.V. 1968. Ecological correlation of water loss in burrowing reptiles. Nature 218: 659-660.

Lepsch, I.F. 2010. Formação e Conservação dos Solos. 2 ed. São Paulo, Oficina de Textos. 216p.

Lima, F.A.N.S; Gasparini, J.L.; Almeida, A.P.; Vital, M.V.C. \& Mott, T. 2014. Sexual dimorphism in Amphisbaena nigricauda (Reptilia, Squamata, Amphisbaenidae) from Southeastern Brazil. Iheringia, Série Zoologia 104(3): 299-307.

López, P., \& Martín, J. 1994. Responses by amphisbaenian Blanus cinereus to chemicals from prey or potentially harmful ant species. Journal of Chemical Ecology 20: 1113-1119.

López, P. \& Salvador, A. 1994. Tongue-flicking prior to prey attack by the amphisbaenian Blanus cinereus. Journal of Herpetology 28: 502-504.

López, P.; Cooper, W.E.Jr \& Salvador, A. 1997. Discrimination of self from other males by chemosensory cues in the amphisbaenian (Blanus cinereus). Journal of Comparative Psychology 111: 105-109.

López, P.; Salvador, A. \& Martín, J. 1998. Soil temperatures, rock selection and the thermal ecology of the amphisbaenian reptile Blanus cinereus. Canadian Journal Zoology 76: 673-679. 
López, P. \& Martin, J. 2001. Chemosensory predator recognition induces specific defensive behaviours in a fossorial amphisbaenian. Animal Behavior 62: 259-264.

López, P.; Civantos, E. \& Martín, J. 2002. Body temperature regulation in the amphisbaenian Trogonophis wiegmanni. Canadian Journal of Zoology 80: 42-47.

López, P. \& Martin, J. 2005. Intersexual differences in chemical composition of precloacal gland secretions of the amphisbaenian Blanus cinereus. Journal of Chemical Ecology 31(12): 2913-2921.

López, P.; Martin, J. \& Salvador, A. 2013. Flexibility in feeding behaviour may compensate for morphological constraints of fossoriality in the amphisbaenian Blanus cinereus. Amphibia-Reptilia 34: 241-247.

Kearney, M. 2003. Systematics of the Amphisbaenia (Lepidosauria: Squamata) based on morphological evidence from recent and fossil forms. Herpetological Monographs 17: 1-74.

Maisano, J.A.; Kearney, M. \& Rowe, T. 2006. Cranial anatomy of the spade-headed amphisbaenian Diplometopon zarudnyi (Squamata, amphisbaenia) based on high-resolution X-ray computed tomography. Journal of Morphology 267: 70-102.

Martín, J.; López, P. \& Salvador, A. 1990. Field body temperatures of the amphisbaenid lizard Blanus cinereus. Amphibia-Reptilia 11: 87-96.

Martín, J.; López, P. \& Salvador A. 1991. Microhabitat selection of the amphisbaenian Blanus cinereus. Copeia 4: 1142-1146.

Martín, J.; Polo-Cavia, N.; Gonzalo, A.; López, P. \& Civantos, E. 2012. Sexual dimorphism in the North African amphisbaenian Trogonophis wiegmanni. Journal of Herpetology 46: 338-341.

Martín, J.; López, P. \& García, L.V. 2013. Soil characteristics determine microhabitat selection of the fossorial amphisbaenian Trogonophis wiegmanni. Journal of Zoology 290: 265-272.

Martín, J.; Ortega, J.; López, P.; Pérez-Cembranos, A. \&. Pérez-Mellado, V. 2013. Fossorial life does not constrain diet selection in the amphisbaenian Trogonophis wiegmanni. Journal of Zoology 291(3): 226233.

Matias, N.R. \& Verrastro, L. 2018. Thermal biology of Amphisbaena munoai (Squamata: Amphisbaenidae).

Zoologia 35: e2 4574: 1-9. Disponível em: <http://www.scielo.br/pdf/zool/v35/1984-4689-zool-35e24574.pdf>. Acesso em: 19 mar. 2019.

Mott, T. \& Vieites, D.R. 2009. Molecular phylogenetics reveals extreme morphological homoplasy in Brazilian worm lizards challenging current taxonomy. Molecular Phylogenetics and Evolution 51: 190-200. Navega-Gonçalves, M.E.C. 1997. Estudo Anatômico de Amphisbaenia mertensi Strauch, 1881 (Reptilia, Amphisbaenia, Amphisbaenidae). Dissertação (Mestrado em Zoologia). Universidade de São Paulo, São Paulo, SP. 109p.

Navega-Gonçalves, M.E.C. 2002. Morfologia comparada de seis espécies de Amphisbaenidae (Squamata, 
Amphisbaenia). Tese (Doutorado em Zoologia). Universidade de São Paulo, São Paulo, SP. 168p.

Navega-Gonçalves, M.E.C. 2004. Anfisbênias: quem são essas desconhecidas? Ciência Hoje 34(204): 6668.

Navega-Gonçalves, M.E.C. 2009. Anatomia visceral comparada de Amphisbaenidae (Squamata, Amphisbaenia). Zoologia 26(3): 511-526.

Navega-Gonçalves, M.E.C. \& Souza, A.M. 2001. Anatomia visceral de Amphisbaena mertensi Strauch, 1881 (Reptilia, Amphisbaenia, Amphisbaenidae). Papéis Avulsos de Zoologia 41(26): 489-518.

Navega-Gonçalves, M.E.C. \& Silva, J.R.M.C. 2013. Sistema respiratório de Amphisbaena vermicularis Wagler, 1824 e Amphisbaena microcephala (Squamata, Amphisbaenia, Amphisbaenidae). Iheringia, Série Zoologia 103(1): 20-30.

Packard, G.C.; Tracy, R. \& Roth, J.J. 1977. The physiological ecology of reptilian eggs and embryos, and the evolution of viviparity within the class Reptilia. Biological Reviews 52(1):71-105.

Papenfuss, T.S. 1982. The ecology and systematics of the amphisbaenian Bipes. Occasional Pappers on the California Academy of Sciences, 136: 1-42.

Pavan, D. 2007. Assembléias de répteis e anfíbios do Cerrado ao longo da bacia do rio Tocantins e o impacto do aproveitamento hidrelétrico da região na sua conservação. Tese (Doutorado em Zoologia). Universidade de São Paulo, São Paulo, SP. 414p.

Porto, M.; Soares, M. \& Caramaschi, U. 2000. A new species of Leposternon Wagler, 1824 from Minas Gerais, Brazil, with a key to the species of the genus (Amphisbaenia, Amphisbaenidae). Boletim do Museu Nacional, Nova série, Zoologia 412: 1-10.

Pough, F.H.; Janis, C.M. \& Heiser, J.B. 2008. A vida dos Vertebrados. 4 ed. São Paulo, Atheneu Editora. $684 p$.

Pregill, G. 1984. Durophagous feeding adaptations in an amphisbaenid. Journal of Herpetology 18(2): 186191.

Saint Girons, H. 1971. Quelques facteurs du rythme circadien d'activité chez les lepidosauriens (reptiles). Bulletin de la Socièté Zoologique de France 96(3): 317-330.

Santos, L.C. 2013. Biologia reprodutiva comparada de Amphisbaenidae (Squamata, Amphisbaenia) do Brasil. Tese (Doutorado em Ciências). Faculdade de Medicina Veterinária e Zootecnia da Universidade de São Paulo, São Paulo, SP. 260p.

Sawaya, P. \& Aguiar, E.P.S. 1982. Water permeability of the tegumento of Amphisbaena alba L. (ReptiliaLacertilia). Brazilian Journal of Medical and Biological Research 15(4-5): 329.

Schmidt-Nielsen, K. 2002. Fisiologia Animal: Adaptação e Meio Ambiente. 5 ed. São Paulo, Livraria Santos Editora. 611p. 
Semhan, R.V.; Monique Halloy, M. \& Montero, R. 2010. Chemical prey discrimination of termites in Amphisbaena heterozonata (Reptilia: Squamata): A learned trait? Journal of Herpetology, 44(3): 489-492. Shine, R. 1985. The Evolution of Viviparity in Reptiles: An Ecological Anlysis, pp. 605-694. In: Gans, C. \& Billet, F. (eds.). Biology of Reptilia. New York, Wiley \& Sons. v. 15.

Sindaco, R.; Kornilios, P.; Sacchi, R. \& Lymberakis, P. 2014. Taxonomic reassessment of Blanus strauchi (Bedriaga,1884) (Squamata: Amphisbaenia: Blanidae), with the descriptionof a new species from south-east Anatolia (Turkey). Zootaxa 3795(3): 311-326. Disponível em: <https://biotaxa.org/Zootaxa/article/view/zootaxa.3795.3.6>. Acesso em: 27 fev. 2019.

Smalian, C. 1884. Beiträge zur Anatomie der Amphisbaeniden. Zeitschrift Für Wissenschaftliche Zoologie 42(1): 126-202.

Strussmann, C. \& Carvalho, M.A. 2001. Two new species of Cercolophia Vanzolini, 1992 from the state of Mato Grosso, western Brazil (Reptilia, Amphisbaenia, A1nphisbaenidae). Bollettino del Museo Regionale di Scienze Naturali di Torino 18(2): 487-505.

Tavares, A.P.G.; Carvalho, J.J.S. \& Ribeiro, L.B. 2017. First record of Amphisbaena lumbricalis (Squamata, Amphisbaenidae) in the state of Pernambuco, Brazil: including a distribution map and soil classification of its occurrence. Herpetology Notes 10: 19-22. Disponível em: <https://biotaxa.org/hn/article/view/26179>. Acesso em: 27 mar. 2019.

Tossini, G.; Jones, S. \& Avery, R.A. 1994. Effects of feeding on set point temperatures and thermoregulatory behaviour in the lizards Podarcis muralis and Lacerta vivipara. Amphibia-Reptilia 15: 257-265.

Uetz, P.; Freed, P. \& Hošek, J. (eds.). 2019. The Reptile Database. Disponível em: <http://www.reptiledatabase.org>. Último acesso em: 04 set. 2019.

Vanzolini, P.E. 1951. Evolution, adaptations and distribution of the amphisbaenid lizards (Sauria: Amphisbaenidae). Thesis (Doctor of Philosophy in Biology). Harvard University, Cambridge, EUA. 148p. Vanzolini, P.E. 1991a. Biometry and geographical differentiation of Amphisbaena roberti Gans, 1964 (Reptilia, Amphisbaenia). Papéis Avulsos de Zoologia 37(24): 363-377.

Vanzolini, P.E. 1991b. A third species of Bronia Gray 1865 (Reptilia, Amphisbaenia). Papéis Avulsos de Zoologia 37(25): 379-388.

Vanzolini, P.E. 1992. Cercolophia, a new genus for the species of Amphisbaena with a terminal vertical keel on the tail (Reptilia, Amphisbaenia). Papéis Avulsos de Zoologia 37(27): 401-412.

Vanzolini, P.E. 1996. On slender species of Amphisbaena, with the description of a new one from Northeastern Brasil (Reptilia, Amphsibaenia). Papéis Avulsos de Zoologia 39(16): 293-305.

Vanzolini, P.E. 1999. On Anops (Reptilia: Amphsibaenia: Amphisbaenidae). Papéis Avulsos de Zoologia 
41(1): 1-37.

Vanzolini, P.E. 2002. An aid to the identification of the South American species of Amphisbaena (Squamata, Amphisbaenidae). Papéis Avulsos de Zoologia 42(15): 351-362.

Vidal, N.; Azvolinsky, A.; Cruaud, C. \& Hedges, S.B. 2008. Origem of tropical Americam burrowing reptiles by transatlantic rafting. Biology Letters 4: 115-118.

Vidal, N. \& Hedges, S.B. 2009. The molecular evolutionary tree of lizards, snakes, and amphisbaenians, Comptes Rendus Biologies 332: 129-139.

Vieira, M.I.; Alves, M.L.M \& Fabian-Beurmann, M.E. 1980. Osteologia craniana de Amphisbaena darwini trachura Cope, 1885 (Lacertilia-Amphisbaenidae). Iheringia, Série Zoologia 55: 87-106.

Webb, J.K.; Shine, R.; Branch, W. \& Harlow, P.S. 2000. Life underground: foods and reproductive biology of two amphisbaenian species from Southern Africa. Journal of Herpetology 34: 510-516.

Westphal, N.; Mahlow, K.; Head, J.J. \& Müller, J. 2019. Pectoral myology of limb-reduced worm lizards (Squamata, Amphisbaenia) suggests decoupling of the musculoskeletal system during the evolution of body elongation. BMC Evolutionary Biology 19(16): 1-23. Disponível em: <https://bmcevolbiol.biomedcentral.com/articles/10.1186/s12862-018-1303-1> Acesso em: 10 de set. 2019.

Wever, E.G. \& Gans, C. 1972. The ear and hering in Bipes biporus. Proceedings of the National Academy Sciences 69(3): 2714-2716.

Wever, E.G. \& Gans, C. 1973. The ear in Amphisbaenia (Reptilia), further anatomical observations. Journal of Zoology 171: 189-207.

Zangerl, R. 1944. Contributions to the Osteology of the Skull of the Amphisbaenidae. American Midland Naturalist 31: 417-454. 